\title{
Pankkisektorin luottotappioiden ja maatalouden vakuuksien arvon kehitys: Toimiiko maatalousrahoitus riskin hajauttajana?
}

Petri Liesivaara

OP Ryhmä, Gebhardinaukio 1,00100,Helsinki, petri.liesivaara@op.fi

\section{TIIVISTELMÄ}

Maatalouden rahoitus on vakuudellista luotonantoa. Vakuuksien avulla vähennetään pankin luottotappion riskiä. Vakuuden arvoon kuitenkin liittyy epävarmuutta. Rahoituslaitoksen on siis jatkuvasti arvioitava, kuinka paljon sillä on odotettavissa tappioita myöntämästään rahoituksesta. Pitkän aikavälin tuottojen on katettava pitkän aikavälin luottotappiot. Vakuudellisessa rahoituksessa tappioita voidaan estimoida lainan vakuutena olevien omaisuuserien arvon kehittymisen kautta. Tässä tutkimuksessa tarkastelimme peltomaan arvon kehittymistä suhteessa pankkisektorin kokonaisluottotappioihin. Tavoitteena oli selvittää, seuraavatko maatalouden omaisuuserien arvon kehittyminen pankkisektorin yhteenlaskettuja luottotappioita. Trendikorjattujen ja yhteismitallistettujen aikasarjojen tarkastelusta ilmeni, että peltomaan arvon kehittymisellä ei ole yhteyttä Suomen pankkisektorin luottotappioiden määrään. Tulokset antavat viitteitä siitä, että taloudellinen taantuma ei ole heijastunut maatilojen omaisuuden arvoihin. Näin ollen maatalouden rahoitus on historiallisesti toiminut luottosalkun hajauttamisessa hyvin.

Asiasanat: maatalouden rahoitus, luottoriski, luottotappiot

\section{Johdanto}

Maatalouden rahoitus on vakuudellista luotonantoa. Vakuuksien avulla turvataan pankin saatavat tilanteessa, jossa velallinen ei kykene maksamaan velvoitteitaan. Vakuuden arvoon kuitenkin liittyy epävarmuutta. Esimerkiksi taantuman aikana omaisuuserien realisointi on vaikeampaa ja hinta laskee.

Rahoituslaitoksen on jatkuvasti arvioitava, kuinka paljon sillä on odotettavissa tappioita myöntämästään rahoituksesta. Pitkän aikavälin tuottojen on katettava pitkän aikavälin luottotappiot. Kuten kymmenen vuoden takainen finanssikriisi osoitti, monien rahoitusinstrumenttien riskit ovat keskenään korreloituneita taloudellisen taantuman yhteydessä. Tämä korrelaatio tulisi ottaa huomioon, kun arvioidaan rahoituslaitokseen kohdistuvaa kokonaisriskiä. Haasteena kuitenkin on, että korrelaatiota ei useinkaan havaita normaalina talouden aikana.

Rahoituslaitosten sääntelyn vaatimat pääomavaatimukset perustuvat joko standardimalleihin tai pankkien omiin luottoriskimalleihin. Sääntelyn yleisenä tavoitteena on lisätä pankkisektorin kestävyyttä ja estää tilanne, jossa pankkisektorin pääomat eivät riitä kattamaan syntyviä tappioita. Toisin sanoen omia pääomia tulee olla riittävästi luottotappioiden kattamiseen kaikissa olosuhteissa. Pankeille omien luottoriskimallien hyöty on matalampi omien varojen vaade. Lisäksi omien luottoriskimallien etuja ovat riskien hyvä mittaaminen sekä hinnoittelu.

Rahoituslaitosten sisäisten luottoriskimallien merkitys kasvoi entisestään vuonna 2018 uuden kirjanpitostandardin myötä. IFRS9 kirjanpitostandardin mukaan pankkien arvonalentumiset lasketaan sisäisten mallien mukaan. Mallien tulisi huomioida eteenpäin katsova informaatio, mikä tarkoittaa esimerkiksi makrotaloudellisten ennusteiden soveltamista. Lisäksi vuoden 2021 aikana Euroopan keskuspankki saattaa päätökseen mittavan vakavaraisuuslaskennan luottoriskimallien ohjeistuksen, joka käytännössä yhtenäistää ja selkeyttää pankkien sisäisesti käyttämät määrittelyt ja mallien hallinnoinnin.

Niin pääomavaateen laskenta kuin arvonalentumisten määrittäminen koostuvat kolmesta tekijästä, maksukyvyttömyyden todennäköisyydestä (probability of default, PD), tappio-osuudesta (loss given default, LGD) sekä vastuun määrästä (exposure at default, EAD). PD:n ja LGD:n korrelaatio talouden suhdanteissa on avainasemassa, kun arvioidaan pääomien riittävyyttä. Maksukyvyttömyyden todennäköisyyden ennusteella arvioidaan millä todennäköisyydellä yksittäinen asiakas tai luotto menee maksukyvyttömäksi seuraavien 12 kuukauden aikana. Arvonalentumisten laskennassa sen sijaan lasketaan maksukyvyttömyyden 
todennäköisyyttä koko luoton elinajalle. Tappio-osuudella ennustetaan sitä, kuinka suuri tappio maksukyvyttömyydestä luottolaitokselle koituu. Vakavaraisuuslaskennan kehikossa maksukyvyttömyyden todennäköisyys tulee vastata pitkän aikavälin keskiarvoa, kun tappio-osuudessa tulee estimoida taantuman aiheuttamat tappiot rahoituslaitoksille.

Kirjallisuus luottoriskimalleista on kehittynyt Baselin komitean kiinnitettyä huomiota... Myös maataloussektorin luottoriskimalleista on kohtalaisen paljon kirjallisuutta. Maatilojen maksukyvyttömyyden todennäköisyyttä on tutkittu muun muassa Ranskassa (Jouault ja Featherstone 2011) ja Yhdysvalloissa (Featherstone ym. 2006, Katchova ja Barry 2005). Maksukyvyttömyyden todennäköisyyttä ennustavien mallien kehitys on edellä toteutuneiden tappioiden mallien kehittymistä. Maatalousrahoituksen tappioiden suuruutta on kuitenkin käsitelty muun muassa luottojen hinnoittelun kannalta (Featherstone ja Boessen 1994), luottoriskien vakuuttamisen kannalta (Sherrick ym. 2000) ja portfolion kokonaistappioiden näkökulmasta (Zech ja Pedersen 2004, Dressler ja Tauer 2016). Yan ja Barry (2006) tarkastelivat pellon arvon muutosten aiheuttamaa luottoappioiden riskiä.

Tässä tutkimuksessa tarkasteltiin maatalousrahoituksen yhden yleisimmän vakuuslajin, peltomaan, arvon yhteyttä pankkisektorin kokonaisluottotappioihin. Tavoitteena oli selvittää, kuinka korreloituneita vakuuksien arvot ovat historiallisesti olleet koko pankkisektorin luottotappioihin. Tulosten avulla voidaan paremmin ymmärtää, miten maatalouden suhdanteet tai vakuuksien arvot ovat yhteydessä rahoitussektorin vakauteen erityisesti tulevaisuudessa. Seuraavassa luvussa käydään lyhyesti läpi analyysissä käytettävät aineistot. Tämän jälkeen esitellään tutkimusmenetelmät ja tulokset. Viimeisessä luvussa esitetään analyysin johtopäätökset.

\section{Aineisto ja menetelmät}

Tutkimuksen aineistona käytetään kahta julkista tilastoa, Maanmittauslaitoksen peltojen hinta tilastoa sekä Finanssivalvonnan tilastoimia pankkien yhteenlaskettuja luottotappioita. Alla olevassa kuvassa (Kuva 1) on esitetty pankkien nettoluottotappio vuosina 1990-2010.

1990-luvun alussa luottotappioiden määrä kasvoi ennätyssuuriksi. Vuosina 1991-1994 yhteenlaskettu luottotappioiden määrä kasvoi lähes 10 miljardiin Euroon. 2000-luvun alussa luottotappioiden määrä oli erittäin alhainen. Vuonna 2009 kansainvälinen finanssikriisi näkyi Suomessa ainoastaan 766 miljoonan Euron suuruisina luottotappioina, jotka ovat erittäin maltilliset 1990-luvun lamaan verrattuna.

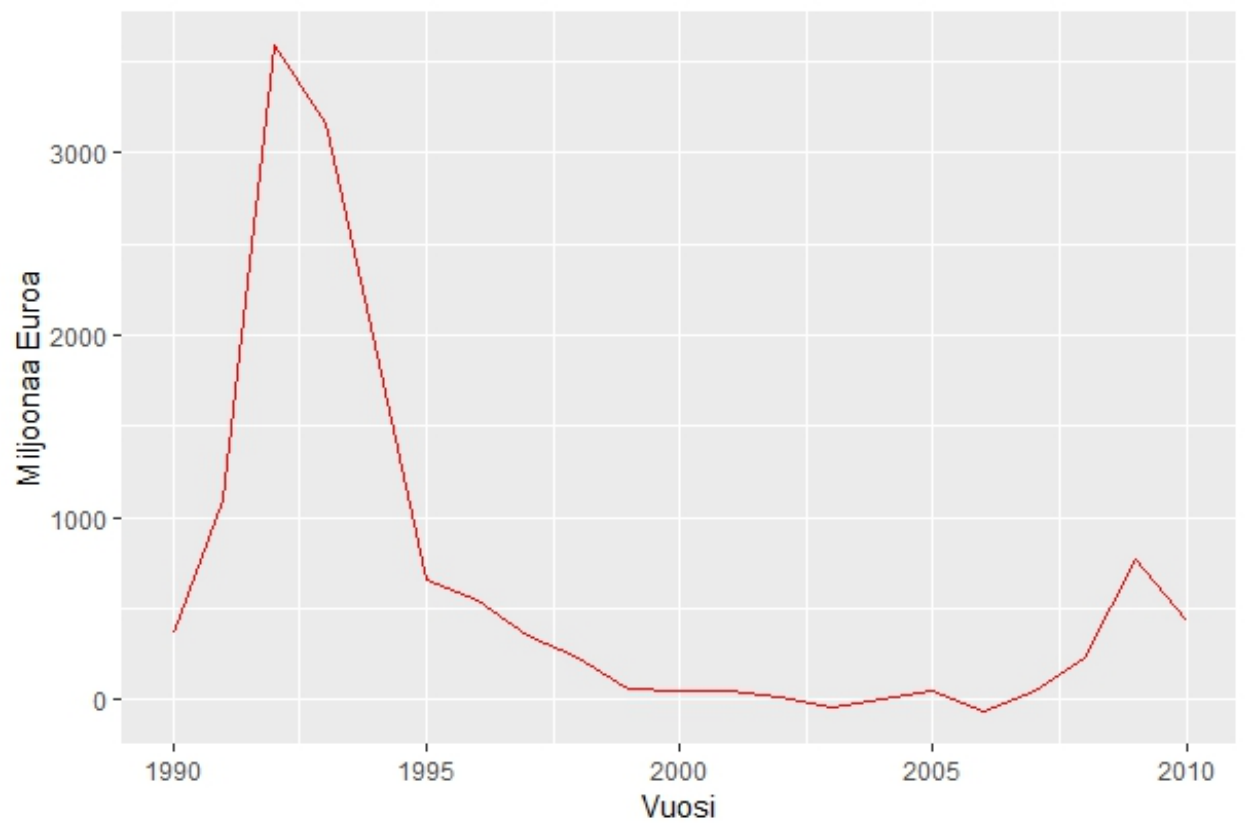

Kuva 1. Pankkisektorin nettoluottotappiot 1990-2010 (Tilastokeskus 2019) 
Toisen osion tämän tutkimuksen aineistosta muodostaa pellon hinta tilasto, jota ylläpitää Maanmittauslaitos. Tätä tutkimusta varten käytettiin yli 2 ha pelkkää peltomaata sisältäneiden kauppojen mediaanihintoja vuosilta 1990-2019. Peltomaan kauppahinnat sisältävät ainoastaan välittäjän kautta tehdyt kauppahinnat. Mediaanihinnan kehitys on esitetty Kuvassa 2. Pellon hinta laski 1990-luvun laman aikana ja hinnat pysyivät matalalla EU-jäsenyyttä seuranneiden vuosien ajan. Pellon hinta lähti nousuun vasta vuonna 1997. Tämän jälkeen hinnat nousivat yhtäjaksoisesti vuoteen 2009 asti.

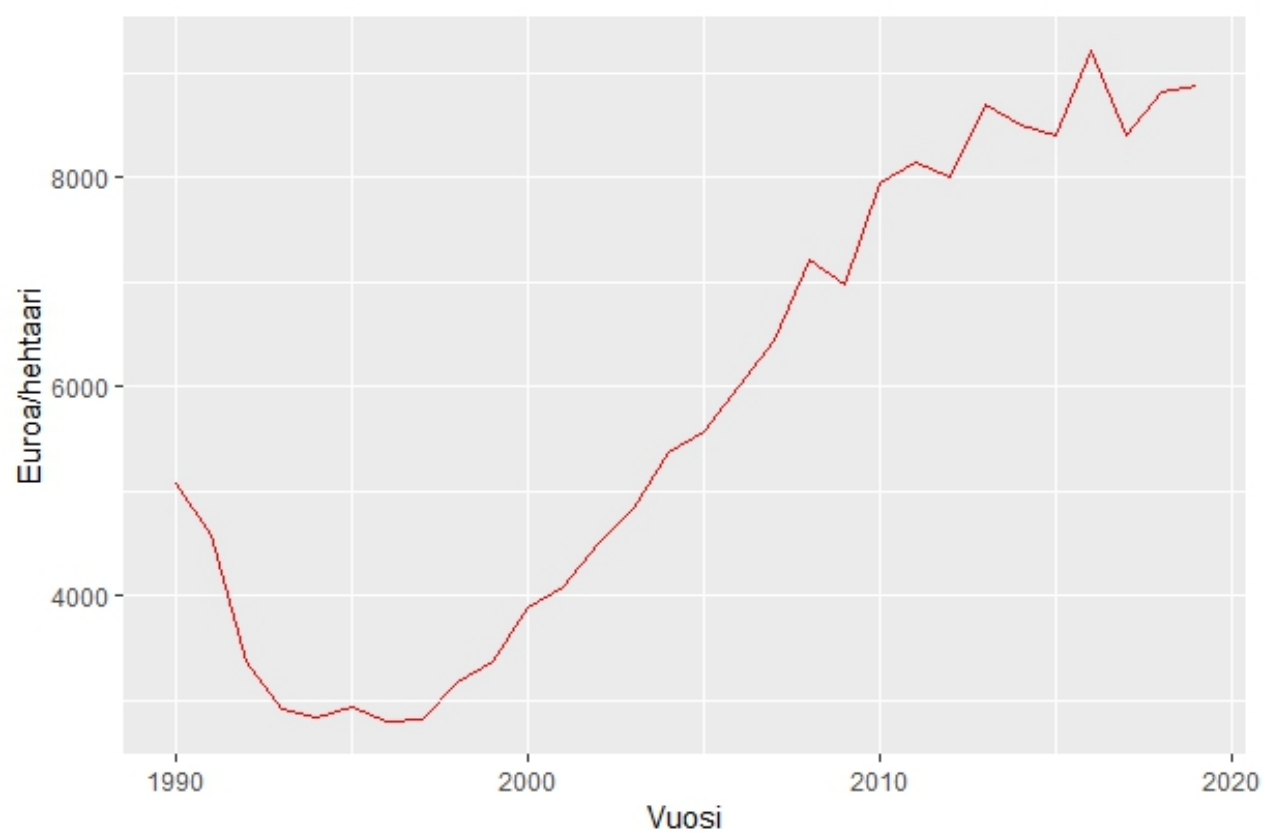

Kuva 2. Peltomaan myyntihinnan mediaani yli 2 hehtaaria pelkästään peltomaata sisältävissä kaupoissa (Maanmittauslaitos 2019)

Peltomaan arvon kehittymisen ja pankkien luottotappioiden korrelaatiota tutkittiin pienimmän neliösumman menetelmällä (OLS) eli lineaarisella regressiolla. Ennen analyysin suorittamista aikasarjat trendikorjattiin ja yhteismitallistettiin. Trendikorjaus suoritettiin ottamalla aikasarjoista ensin luonnolliset logaritmit ja sen jälkeen logaritmeistä vuosimuutokset. Vuosimuutosten yhteismitallistaminen tehtiin normalisoimalla aikasarjat z-arvoiksi.

Estimoitavat mallit ovat muotoa:

$$
Y_{t}=\beta_{0}+\beta_{1} x_{0}+\beta_{2} x_{-1}+\cdots \beta_{n} x_{-n}
$$

missä $Y$ on pankkien trendikorjatut ja normalisoidut luottotappioiden muutokset vuotena $t$ ja $x$ on trendikorjatut ja normalisoidut pellon hinnan muutokset.

\section{Tulokset}

Regressiomallin keskeisimmät tulokset on esitetty ohessa olevassa taulukossa (Taulukko 1). Luottotappioita selittäväksi tekijäksi testattiin pellon hinnan muutoksia aina neljään vuoteen myöhästettyjä arvoja. Kaikkien mallien selitysasteet jäivät mataliksi, eikä pellon hinnan sekä pankkien nettoluottotappioiden väliltä löydetty tilastollisesti merkitsevää yhteyttä. Tulokset viittaavat siihen, että pellon hinnalla ja pankkien nettoluottotappioilla ei ole tilastollisesti merkitsevää yhteyttä. 
Taulukko 1. Regressiomallien tulokset.

\begin{tabular}{|c|c|c|c|}
\hline Riippumattomat muuttujat & Regressiomalli 1 & Regressiomalli 2 & Regressiomalli 3 \\
\hline \multirow{2}{*}{ Vakiotermi } & -0.01392 & -0.21526 & -0.02882 \\
\hline & $(0.63600)$ & $(0.34389)$ & (0.23893) \\
\hline \multirow{2}{*}{$p$} & -0.19540 & & \\
\hline & $(0.89466)$ & & \\
\hline \multirow{2}{*}{ p_lag_1 } & 0.37966 & 0.53442 & 0.09868 \\
\hline & $(0.80158)$ & $(0.61074)$ & $(0.24492)$ \\
\hline \multirow{2}{*}{ p_lag_2 } & -0.31548 & & \\
\hline & $(0.77415)$ & & \\
\hline \multirow{2}{*}{ p_lag_3 } & 0.22225 & & \\
\hline & $(0.55849)$ & & \\
\hline \multirow{2}{*}{ p_lag_4 } & 0.07363 & 0.01403 & \\
\hline & $(0.51352)$ & (0.29971) & \\
\hline R2 & 0.09061 & 0.06688 & 0.009459 \\
\hline
\end{tabular}

\section{Johtopäätökset}

Trendikorjattujen ja yhteismitallistettujen aikasarjojen tarkastelusta ilmeni, että peltomaan arvon kehittymisellä ei ole yhteyttä Suomen pankkisektorin luottotappioiden määrään. Tulokset antavat viitteitä siitä, että maatilojen omaisuuden arvojen muutos ei ole ollut yhteydessä pankkisektorin luottotappioihin. Näin ollen maatalouden rahoitus on historiallisesti toiminut luottosalkun hajauttamisessa hyvin. Tuloksien arvioinnissa tulee kuitenkin ottaa huomioon, että tässä tutkimuksessa ei käsitelty pankkien luottotappioita maatalousrahoituksesta, vaan luottotappioiden riskiä arvioitiin välillisesti pellon hinnan kautta.

Viime kädessä maatalousrahoituksen toteutuneet luottotappiot määrittävät maatalousrahoituksen ja taantuman välisen yhteyden. Yksittäiselle alueelle tai pankille maatalouden luottotappiot voivat olla merkittäviä. Toisaalta toteutuneita maksukyvyttömyyksiä ei tarkasteltu. Maksukyvyttömyyksien määrä saattaa olla kasvanut taantuman aikana, mutta turvaavien vakuuksien takia toteutuneet luottotappiot jäävät mataliksi (Yan ja Barry, 2006).

Aineistojen visuaalinen tarkastelu osoittaa, että 1990-luvun lamassa pellon hinta laski samaan aikaan, kun pankkien luottotappiot nousivat ennätyskorkeiksi. Tässä analyysissä sovelletussa menetelmässä on oletettu normaalijakautuneisuus, jonka paikkansapitävyys erityisesti taantuman yhteydessä voidaan kyseenalaistaa. Tutkimuksissa on todettu, että taantumassa luottotappioiden määrä on vahvasti korreloitunut, mutta normaalissa talouden suhdanteessa korrelaatiota ei ole (Schmitt ym. 2015). Näin ollen korrelaatio eri portfolioiden tai sektorien tappioiden välillä on tappioiden jakauman hännissä, jolloin normaalijakauman olettama ei enää päde. Aikasarjojen korrelaation tutkimista copula malleilla tulisi jatkaa, jotta mahdolliset epäsymmetriset korrelaatiorakenteet saataisiin paljastettua.

Pääomavaateiden ja arvonalentumisten laskemisessa rahoituslaitosten on jatkuvasti arvioitava, kuinka luotettavasti vakuuksien arvojen avulla tai luottotappioiden määrästä voidaan tehdä johtopäätöksiä kehityksestä tulevaisuudesta. Pankkien toimintaympäristö on tällä hetkellä murroksessa. Uusia tuotteita kehitetään ja kilpailijoiden määrä kasvaa. Kiristyvä sääntely asettaa kustannuspaineita toiminnalle. Toisaalta matala korkotaso haastaa tuloksentekokykyä. Maatalous käy sektorina läpi hitaasti, mutta vakaasti jatkuvaa rakennemuutosta. Tilojen määrä vähenee sekä jatkavien tilojen koko kasvaa ja ammattimaistuu. Avainasemassa on niiden mekanismien tunteminen, jotka yhdistävät maatalouden rahoituksen ja luottojen myöntämiseen liittyvät riskit yleisiin talouden suhdanteisiin. Mekanismien tuntemisen ohella realistinen kuva toimialan tulevaisuudesta varmistaa, että rahoitus on pitkällä aikavälillä kestävää. Tämä on ensiarvoisen 
tärkeää, sillä maataloudessa rahoituspäätökset ulottuvat aina 15 vuoteen asti. Tulevaisuuskuvan luominen onkin yksi keskeisistä, mutta samalla haastavimmista jatkotutkimuksen tarpeista.

\section{Kirjallisuus}

Dressler, J.B. \& Tauer, L.W. 2016. Estimating expected and unexpected losses for agricultural mortgage portfolios. American Journal of Agricultural Economics 98: 1470-1485. https://doi.org/10.1093/ajae/aaw049

Featherstone, A.M. \& Boessen, C.R. 1994. Loan loss severity of agricultural mortgages. Applied Economic Perspectives and Policy 16: 249-258. https://doi.org/10.2307/1349467

Featherstone, A.M., Roessler, L.M. \& Barry, P.J. 2006. Determining the probability of default and risk-rating class for loans in the seventh farm credit district portfolio. Applied Economic Perspectives and Policy 28: 4-23. https://doi.org/10.1111/j.1467-9353.2006.00270.x

Tilastokeskus 2019. Kotimaisten pankkien luottotappiot. https://www.stat.fi/til//lai/2005/04/1lai_2005_04_200605-31_tau_004.html

Jouault, A. \& Featherstone, A.M. 2011. Determining the probability of default of agricultural loans in a French bank. Journal of Applied Finance \& Banking 1: 1-30.

Katchova, A.L. \& Barry, P.J. 2005. Credit risk models and agricultural lending. American Journal of Agricultural Economics 87: 194-205. https://doi.org/10.1111/j.0002-9092.2005.00711.x

Maanmittauslaitos 2019. Maanmittauslaitoksen tilastopalvelu. https://khr.maanmittauslaitos.fi/

Schmitt, T.A., Schäfer, R. \& Guhr, T. 2015. Credit Risk: taking fluctuating asset correlations into account. Journal of Credit Risk 11: 73-94. https://doi.org/10.21314/JCR.2015.196

Sherrick, B.J., Barry, P.J. \& Ellinger, P.N. 2000. Valuation of credit risk in agricultural mortgages. American Journal of Agricultural Economics 82: 71-81. https://doi.org/10.1111/0002-9092.00007

Yan, Y. \& Barry, P.J. 2006. Loss-given-default on farm real estate loans: probability of full recovery. Agricultural Finance Review 66: 47-59. https://doi.org/10.1108/00214660680001179

Zech, L. \& Pedersen, G. 2004. Application of credit risk models to agricultural lending. Agricultural Finance Review 64: 91-106. https://doi.org/10.1108/00214660480001156 